\title{
170. Analysis of temporary steel grandstand with different bracing systems exposed to crowd load
}

\author{
Natalia Lasowicz ${ }^{1}$, Tomasz Falborski ${ }^{2}$, Robert Jankowski ${ }^{3}$ \\ Gdansk University of Technology, Faculty of Civil and Environmental Engineering, Gdańsk, Poland \\ ${ }^{2}$ Corresponding author \\ E-mail: ${ }^{1}$ natmajew@pg.edu.pl, ${ }^{2}$ tomfalbo@pg.edu.pl, ${ }^{3}$ jankowr@pg.edu.pl
}

Received 7 September 2018; received in revised form 22 November 2018; accepted 30 November 2018 DOI https://doi.org/10.21595/jme.2018.20422

Check for updates

Copyright $(2018$ Natalia Lasowicz, et al. This is an open access article distributed under the Creative Commons Attribution License, which permits unrestricted use, distribution, and reproduction in any medium, provided the original work is properly cited.

\begin{abstract}
Grandstands are structures which are regularly subjected to dynamic loads generated by crowd motions. It is a dangerous situation when spectators induce rhythmic jumping, dancing, stamping, etc. If the synchronized movement of spectators excites a natural frequency of the structure, resonant response might occur. To avoid such situations, temporary steel grandstands are commonly strengthened using additional elements that create bracing system which is selected depending on the size of the structure, type of the event, acting load, etc. It was proved that not only the use but also the arrangement of such structural members is crucial for the dynamic structural resistance. The aim of the present study is to determine the most effective arrangement of bracing system for a typical example of the temporary steel grandstand which is exposed to dynamic load induced by spectators. Three different arrangements of bracing systems have been analysed using five criteria recommended in the literature. The results of the study clearly show that the dynamic parameters of the grandstand are substantially different for various types of bracing systems. The largest improvement in the structural behaviour has been obtained for the grandstand equipped with the bracing system satisfying all proposed criteria. The peak accelerations for this case have been found to be nearly twice as low as for structures with other bracing arrangements. The application of such a system for the grandstand which is exposed to human-induced vibrations allows for safe use of the structure as well as improves comfort of spectators.
\end{abstract}

Keywords: temporary steel grandstand, crowd load, bracing system.

\section{Introduction}

Excessive structural vibrations, due to different dynamic loads, are among the most serious and dangerous scenarios to occur in the case of civil engineering structures (see [1-3] for example). Grandstands are structures which are regularly subjected to dynamic loads generated by crowd motions $[4,5]$. It is a dangerous situation when spectators induce rhythmic jumping, dancing, stamping, etc. [6]. A large number of accidents concerning collapses of steel grandstands were observed in the past as the result of such human-induced vibrations [7].

Steel grandstands are commonly designed as temporary structures, often erected using a scaffolding system. Due to a relatively light weight and slender structural members, such structures are quite vulnerable to dynamic excitations $[8,9]$. If the synchronized movement of spectators excites a natural frequency of the grandstand, resonant response might occur, and this effect can be really fatal for the structure [5]. To avoid such situations, temporary steel grandstands are very often strengthened using additional elements that create bracing system which is selected depending on the size of the structure, type of the event, acting load, etc. [10]. Such elements are mostly diagonal structural members and their application is important during the design process of the grandstand. It was proved that not only the use but also the arrangement of such structural members is crucial for the dynamic structural resistance [11]. An alternative method of reducing grandstand vibrations includes the application of specially designed dampers, e.g. polymer dampers or hybrid tuned mass dampers (see $[8,12,13])$, but this approach is expensive and more 
difficult to be implemented. It should also be added that steel grandstand vibrations act strongly on human perception and comfort [14]. It is therefore necessary to verify also the level of comfort under human-induced vibrations of structures [15].

Motivated by the above arguments, the aim of the present study is to determine the most effective arrangement of bracing system for a typical example of the temporary steel grandstand which is exposed to dynamic load caused by jumping of spectators. Three different arrangements of bracing systems have been analysed using five criteria recommended in the literature (see [11]). Firstly, the dynamic parameters of grandstands, such as modes shapes and corresponding values of natural frequencies, have been calculated and compared. Then, the dynamic transient analysis has been conducted for structures under human-induced vibrations.

\section{Modal analysis}

The first stage of numerical investigation has been devoted to modal analysis. An example of temporary steel grandstand, which can be installed during summer period to watch the beach volleyball matches, has been considered in the analysis. The total dimensions of the structure are: $8.4 \mathrm{~m}$ (length) $\times 5.4 \mathrm{~m}$ (width) $\times 3.42 \mathrm{~m}$ (height). The structure consists of slender tubular structural members that have been modelled by standard two-node beam-column elements, steel platforms and wooden benches that have been generated as standard four-node shell elements available in the program MSC Marc (see Fig. 1). The base of the grandstand has been considered to be fixed only in translational directions, what represents real situation. Steel, as a structural material, has been described by the following values of material properties: $E=210 \mathrm{GPa}, v=0.3$, $\rho=7850 \mathrm{~kg} / \mathrm{m}^{3}$.

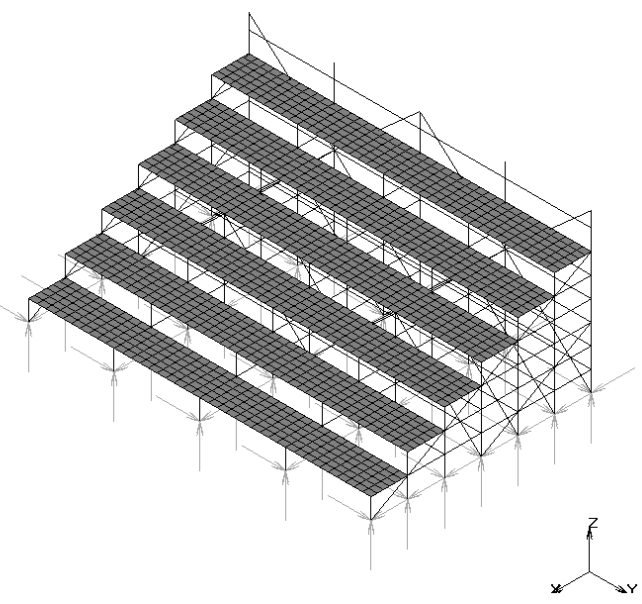

Fig. 1. FE model of a temporary steel grandstand considered in the study

Three numerical models (denoted as Model A, B and C) of a temporary steel grandstand with different arrangements of bracing system have been generated using the following criteria [11]:

(1) Bracing members in different storeys should be provided from the top to the support of the structure,

(2) Bracing members in different storeys should be directly linked where possible,

(3) Bracing members should be linked in the straight line where possible,

(4) Bracing members at the top of adjacent bays should be directly linked where possible,

(5) If extra bracing members are required, they should be used following the above four criteria.

The bracing system used in Model A (see Fig. 2) satisfies first two criteria. In the case of Model B (see Fig. 3), first three criteria have been adopted. In Fig. 4, Model C is shown, in which four more bracing members have been used, so as to satisfy all five criteria. 


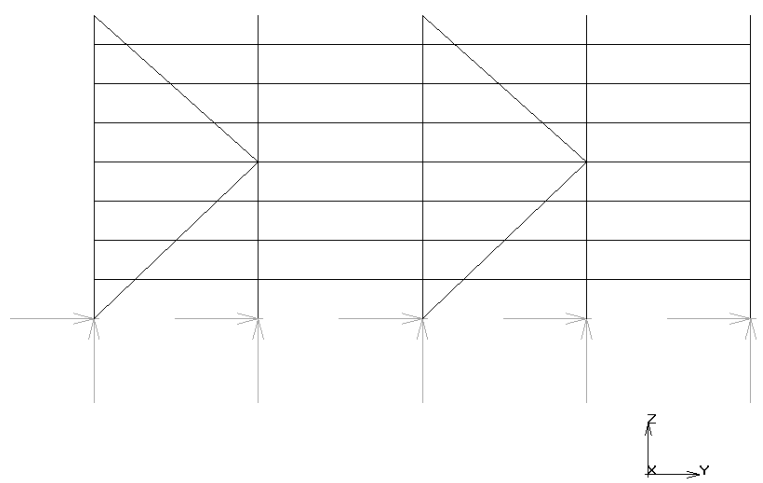

Fig. 2. FE model of a temporary steel grandstand - model A (back view)

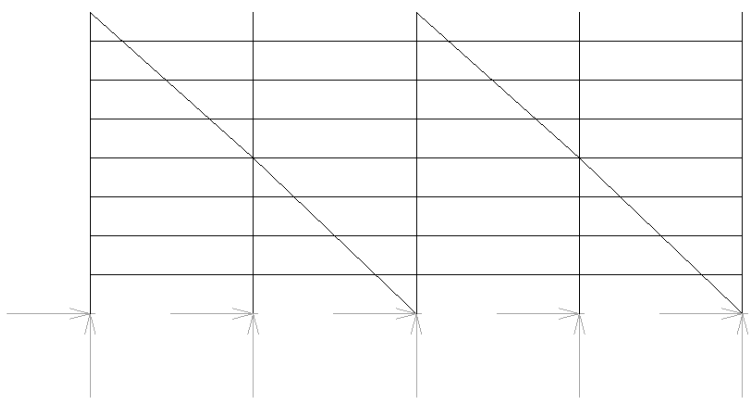

Fig. 3. FE model of a temporary steel grandstand - model B (back view)

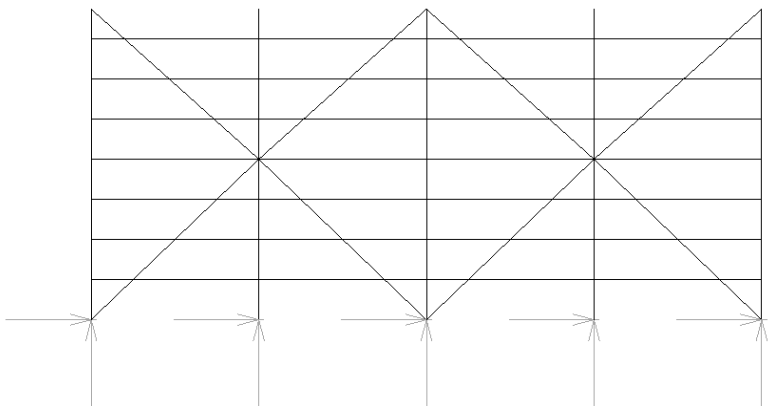

Fig. 4. FE model of a temporary steel grandstand - model C (back view)

Two situations have been analysed in modal analysis. The first one describes an empty grandstand, while the second one considers structure where mass of spectators has been taken into account. The aim of the modal analysis has been related to determination of dynamic parameters, such as mode shapes and corresponding natural frequencies, of empty and occupied temporary grandstands with different arrangements of bracing systems. The examples of the results, in the form of horizontal (sway) mode shapes for all models, are presented in Figs. 5-7, while the corresponding values of natural frequencies are summarized in Table 1.

Table 1. Natural frequencies for all models of a temporary steel grandstand

\begin{tabular}{|c|c|c|}
\hline \multirow{2}{*}{ Model } & \multicolumn{2}{|c|}{ Frequency [Hz] } \\
\cline { 2 - 3 } & Empty structure & Occupied structure \\
\hline Model A & 6.016 & 2.981 \\
\hline Model B & 6.022 & 2.984 \\
\hline Model C & 6.424 & 3.227 \\
\hline
\end{tabular}




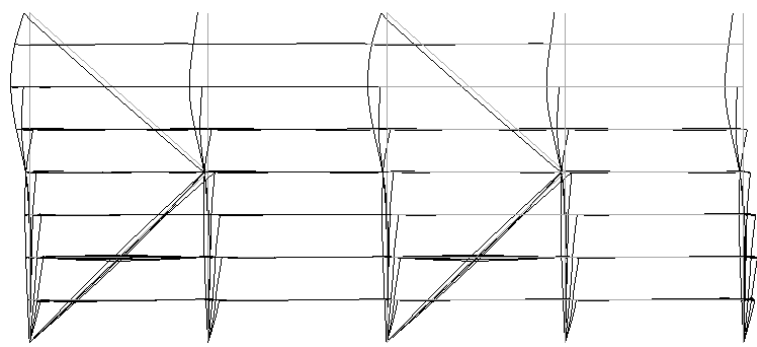

Fig. 5. Horizontal (sway) mode shape for model A (back view)

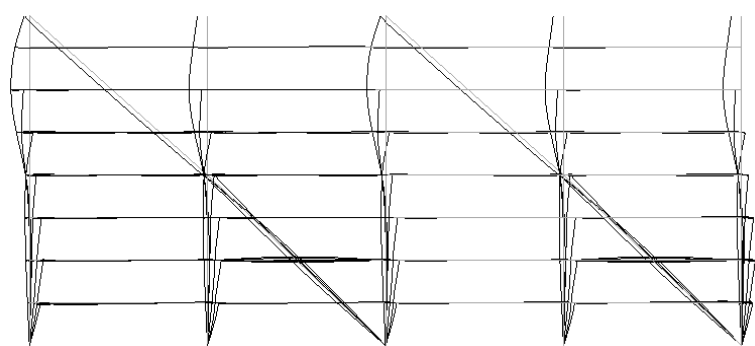

Fig. 6. Horizontal (sway) mode shape for model B (back view)

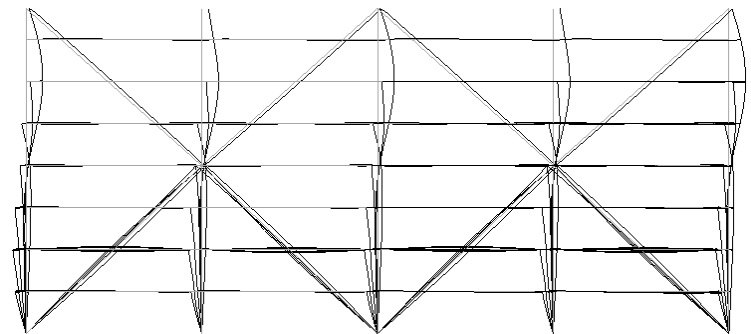

Fig. 7. Horizontal (sway) mode shape for model C (back view)

It can be seen from Table 1 that the mass of spectators leads to substantial reduction in the natural frequency of the grandstand (reduction up to as much as $50.4 \%$ in the case of Model A and Model B). Moreover, the application of bracing system that satisfies all five criteria used in Model C improve the stiffness of the structure considerably. In the case of occupied structure, for example, the increase in the natural frequency for this model is equal to $8.3 \%$ and $8.1 \%$, as compared to Model A and Model B, respectively. It should also be added in this place that, according to the British Standards (see [11] for details), acceptable values of natural frequencies in the horizontal direction for an empty structure cannot be smaller than $4 \mathrm{~Hz}$. On the other hand, in the case of occupied structure, that value cannot be smaller than $2.5 \mathrm{~Hz}$. It can be seen from Fig. 1 that these conditions are satisfied for all models analysed.

\section{Dynamic transient analysis}

The second stage of the numerical study has been devoted to dynamic transient analysis under human-induced vibrations. The aim of the analysis has been related to the determination of peak values of acceleration of the structure equipped with different bracing systems which is exposed to dynamic load due to jumping of spectators. In the analysis, the dynamic load has been assumed to be consisted of synchronous repetitive impacts, as expressed by Fourier series (see [15]):

$F_{S}(t)=G_{S}\left[1+\sum_{n=1}^{\infty} r_{n} \sin \left(\frac{2 n \pi}{T_{p}} t+\varphi_{n}\right)\right]$ 
where $F_{s}(t)$ - dynamic load; $G_{s}$ - weight; $r_{n}$-Fourier coefficient (or dynamic load factor) of the $n$th term; $n$ - number of Fourier terms; $T_{p}$ - period of the jumps; and $\varphi_{n}$ - phase lag of the $n$th term. The full load, as given by Eq. (1) with parameters described in [15], has been applied in the vertical direction assuming that the structure is fully filled by spectators with average mass of each person equal to $100 \mathrm{~kg}$. Additionally, $6 \%$ of the load has also been applied in the horizontal $Y$ (sway) direction, as recommended by the Polish Standard PN-EN 1991-2: 2003 [16]. Dynamic analysis has assumed 10 repetitive cycles describing jumping of spectators at the frequency of $2 \mathrm{~Hz}$. The examples of the results showing the acceleration time histories for all models in $Y$ (sway) direction obtained at the level of the highest platform are presented in Figs. 8-10. Moreover, the peak values of accelerations for sway vibrations ( $Y$ direction) of the temporary steel grandstand equipped with different types of bracing systems under human-induced excitation due to jumping have also been summarized in Table 2 .

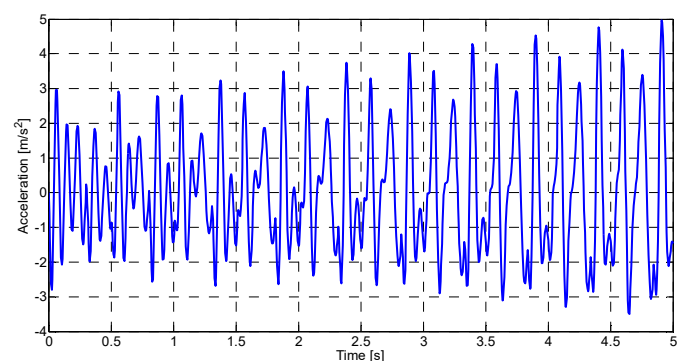

Fig. 8. Acceleration time history for Model A ( $Y$ direction)

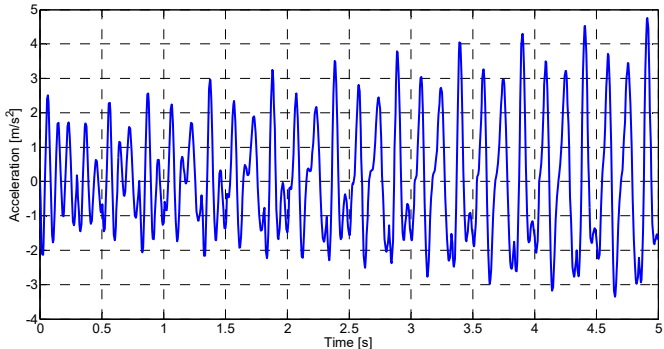

Fig. 9. Acceleration time history for Model B ( $Y$ direction)

Table 2. Peak horizontal (sway) accelerations for all models

\begin{tabular}{|c|c|}
\hline Model & Acceleration $\left[\mathrm{m} / \mathrm{s}^{2}\right]$ \\
\hline Model A & 4.971 \\
\hline Model B & 4.757 \\
\hline Model C & 2.771 \\
\hline
\end{tabular}

It can be seen from Fig. 8-10, as well as from Table 2, that peak value of acceleration estimated for Model C is substantially lower than for the case of Model A and Model B. The reduction is as large as $44.3 \%$ and $41.7 \%$, when comparing Model C to Model A and Model B, respectively. These results clearly indicate that the application of bracing system that satisfies all five criteria is the best solution for the temporary grandstand analysed.

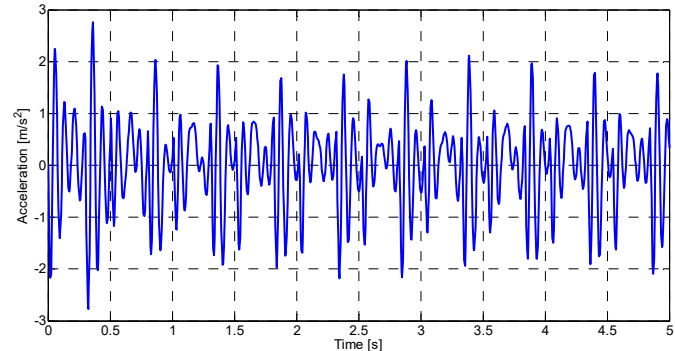

Fig. 10. Acceleration time history for model $\mathrm{C}$ ( $Y$ direction)

\section{Conclusions}

Numerical investigation on a temporary steel scaffolding grandstand equipped with different arrangement of bracing systems exposed to crowd load has been conducted in this paper. Three arrangements of stiffener members, satisfying criteria recommended in the literature, have been 
analysed. In the first stage of the study, modal analysis has been conducted so as to determine dynamic parameters, such as mode shapes and corresponding natural frequencies. In the next step, the dynamic transient analysis has been carried out and the behaviour of the structure under human-induced vibrations due to jumping of spectators has been obtained.

The results of the study clearly show that the response of the analysed temporary steel scaffolding grandstand equipped with different bracing systems is substantially different. The largest improvement in the structural behaviour has been obtained for the grandstand equipped with the bracing system satisfying all criteria proposed. The peak accelerations for this structure have been nearly twice as low as for grandstands with other bracing arrangements.

It should be underlined that bracing members in different levels of the grandstand should be provided from the top to the support of the structure and should be linked in the straight line where possible. Moreover, bracing members in different levels and at the top of adjacent bays should be directly linked where possible. If any extra bracing members are required, they should be used following the above suggestions. The application of such a system for the grandstand which is exposed to human-induced vibrations allows for safe use of the structure as well as improves comfort of spectators.

The analysis described in this paper has been focused on one specific type of steel grandstands which are constructed on specific occasions. Further study is planned to be conducted so as to verify the effectiveness of different bracing systems in the case of other types of such kind of temporary structures. The analysis will also concern the comparison of the structural behaviour when using different bracing systems as well as polymer dampers (see [8, 12]).

\section{References}

[1] Jankowski R. Pounding between superstructure segments in multi-supported elevated bridge with three-span continuous deck under 3D non-uniform earthquake excitation. Journal of Earthquake and Tsunami, Vol. 9, 2015, p. 1550012.

[2] Falborski T., Jankowski R. Experimental study on effectiveness of a prototype seismic isolation system made of polymeric bearings. Applied Sciences, Vol. 7, 2017, p. 808.

[3] Falborski T., Jankowski R. Advanced hysteretic model of a prototype seismic isolation system made of polymeric bearings. Applied Sciences, Vol. 8, 2018, p. 400.

[4] Reynolds P., Pavic A., Ibrahim Z. Changes of modal properties of a stadium structure occupied by a crowd. Proceedings of the International Modal Analysis Conference IMAC-XXII: Conference and Exposition on Structural Dynamics, Dearborn, 2004.

[5] Tatara T., Ptasznik B. Vibrations of sport stadium grandstand structure due to crowd-jumping loads. Proceedings of the 5th International Conference on Computational Methods in Structural Dynamics and Earthquake Engineering, Vol. 2, 2015, p. 2674-2689.

[6] Pan Z., Zhao Y., Chen J. Experimental investigation on coherence factor of rhythmic jumping and its application for simulation of crowd jumping load. Proceedings of the 5th International Conference on Computational Methods in Structural Dynamics and Earthquake Engineering, Vol. 1, 2015, p. 2484-2494.

[7] De Brito V., Pimentel R. Cases of collapse of demountable grandstands. Journal of Performance of Constructed Facilities, Vol. 23, 2009, p. 151-159.

[8] Lasowicz N., Kwiecień A., Jankowski R. Experimental study on the effectiveness of polymer damper in damage reduction of temporary steel grandstand. Journal of Physics, Vol. 628, 2015, p. 012051.

[9] Salyards K. A., Firman III R. J. Human-structure interaction: effects of crowd characteristics. Proceedings of the Society for Experimental Mechanics, Vol. 4, 2011, p. 247-254.

[10] Crick D., Grondin G. Y. Monitoring and Analysis of a Temporary Grandstand. Structural Engineering Report No. 275, Department of Civil and Environment Engineering, University of Alberta, Alberta, 2008.

[11] Ji T., Ellis B. R. Effective bracing systems for temporary grandstands. The Structural Engineer, Vol. 75, 1997, p. 95-100.

[12] Falborski T., Jankowski R., Kwiecień A. Experimental study on polymer mass used to repair damaged structures. Key Engineering Materials, Vol. 488, Issue 489, 2012, p. 347-350. 
[13] Noormohammadi N., Reynolds P. Control of human induced vibrations in stadia using a hybrid tuned mass damper. Proceedings of International Conference on Noise and Vibration Engineering ISMA, 2012, p. 1119-1132.

[14] Nhleko S. P., Williams M. S., Blakeborough A. Vibration perception and comfort level for an audience occupying a grandstand with perceivable motion. Proceedings of the International Modal Analysis Conference IMAC-XXVII, Orlando, 2009.

[15] Ellis B. R., Ji T., Litter J. D. The response of grandstands to dynamic crowd loads. Structures and Buildings, Vol. 140, 2000, p. 355-365.

[16] PN-EN 1991-2: 2003 Actions on Structures - Part 2: Traffic loads on bridges. The European Union Per Regulation, 2003. 